\title{
Removal of vanadium, potassium and iron from spent vanadium catalyst by leaching with citric acid at atmospheric pressure
}

\author{
Krzysztof Mazurek \\ Nicolaus Copernicus University, Faculty of Chemistry, Department of Chemical Technology, ul. Gagarina 7, 87-100 Toruń, \\ Poland, email: mazur@chem.umk.pl
}

\begin{abstract}
The effect of time, temperature, the catalyst particle size and the ratio of the catalyst weight to the leaching solution volume (S:L) on the treatment of spent vanadium catalyst components was determined using citric acid solutions at atmospheric pressure. The optimal parameters of catalyst leaching in $10 \%$ acid solutions at atmospheric pressure are: $\mathrm{T}=323 \mathrm{~K}, \mathrm{t}=4 \mathrm{~h}$, the particle size of less than $0.160 \mathrm{~mm}$, the $\mathrm{S}: \mathrm{L}$ ratio below 0.1 . Under these conditions it was possible to dissolve about $90 \%$ of vanadium and potassium compounds and more than $60 \%$ of iron compounds contained in the catalyst. These results fall within the scope of research on a comprehensive method for recovering spent vanadium catalyst components.
\end{abstract}

Keywords: citric acid, sulphur oxide, spent vanadium catalysts, leaching, recovery.

\section{INTRODUCTION}

In view of the on-going depletion of natural resources and increasing environmental pollution, industrial waste has become a valuable source of raw material acquisition $^{1-7}$. The re-use of waste reduces the exploitation of natural resources and the amount of accumulated waste. The main challenge of the current generation is a sustainable development aimed at reducing the negative impact on the natural environment while maximizing process efficiencies. This also involves the concept of recycling, i.e. the use of resources that were previously considered as waste and that can become a valuable source of raw materials and energy. In 1990, 155 million tons of municipal wastes were landfilled on the area of the current 27 member states of the European Union, and only 28 million tons were recycled or composted. In 2008, the landfill was reduced to 103 million tons, while the amount of recycled waste was increased to 104 million tons. The European Environment Agency estimates that in 2020 this proportion will reach 78 to 136 million tons, respectively ${ }^{8}$.

The same applies to industrial waste. In Poland, over 110 million tons of industrial wastes were "produced" in $2008^{9}$. This waste comes mainly from mining - black coal, brown coal and non-ferrous metals, as well as the processing of these minerals. $75 \%$ of the waste is subjected to land use and the remainder is preserved and stored in a variety of ways.

Spent vanadium catalysts are among the industrial wastes that can be used in the recycling process. It is estimated that the accumulated amount of this waste in Poland is about 3000 tons ${ }^{\mathbf{1 0}}$. The problem of deactivated and decommissioned industrial catalysts has not yet been solved in a comprehensive manner and constitutes a serious problem for plants producing sulphuric(VI) acid. The amount of accumulated waste, the structure complexity and toxicity of some components fully justify the research on a method for recovering spent vanadium catalyst components $^{10-17}$.

Lee et al. $^{\mathbf{1 8}}$ and Zeng \& Cheng ${ }^{\mathbf{1 9}}$ indicated the possibility of using organic acids (oxalic acid and citric acid) for a selective leaching of vanadium compounds from a spent catalyst used in hydrodesulfurization processes (HDS). According to these reports, the use of both leach- ing agents makes it possible to leach vanadium. Oxalic acid has been found to be more selective with respect to vanadium compounds. Citric acid in this study also allowed for the leaching of other metals contained in the catalyst (mainly iron, nickel and molybdenum) ${ }^{\mathbf{1 8}, 19}$. On this basis it was decided to check the possibility of using citric acid as the leaching agent to separate the major components of the spent vanadium catalyst used for the oxidation of $\mathrm{SO}_{2}$ and determine the optimum parameters of leaching process.

\section{EXPERIMENTAL SECTION}

\section{Reagents}

The vanadium spent catalyst used in the study came from a landfill of a plant producing sulphuric(VI) acid with the contact method. The catalyst consisted of: $5.44 \%$ $\mathrm{V}_{2} \mathrm{O}_{5}, 8.57 \% \mathrm{~K}_{2} \mathrm{O}, 0.91 \% \mathrm{Fe}_{2} \mathrm{O}_{3}$. The catalyst was ground and divided into appropriate granulometric fractions. The citric acid used was of analytical grade - POCh Gliwice, $\geq 99 \%$.

\section{Experimental part}

Weighed samples of the catalyst $(5.000 \mathrm{~g})$ were placed in conical flasks with a capacity of $100 \mathrm{~cm}^{3}$, and an appropriate amount of the leaching agent was added using a disposable pipette. The samples were vigorously stirred for a certain time and at a constant temperature. After a suitable time, the samples were filtered with suction and the clear solution was sampled for quantitative analysis.

\section{Analytical methods}

The concentration of all ions in solutions was determined using the EDXRF method, using a PANalytical's MiniPal4 compact energy dispersive X-ray spectrometer ${ }^{20}$.

\section{RESULTS AND DISCUSSION}

The effect of time on the degree of dissolution of the test compounds

Figure 1 shows the relationship between the degree of dissolution of the tested compounds and the leaching process time. The curves show clearly that time plays an 


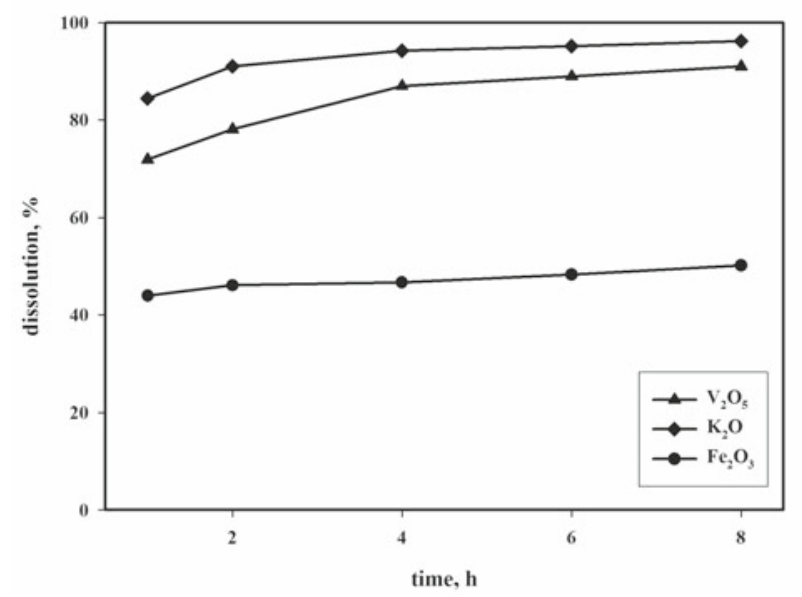

Figure 1. Dissolution of vanadium, potassium and iron compounds as a function of time $(\phi=0.750-0.160 \mathrm{~mm}$; $\mathrm{cC}_{6} \mathrm{H}_{8} \mathrm{O}_{7}=10 \% ; \mathrm{T}=293 \mathrm{~K} ; \mathrm{S}: \mathrm{L}=0.1\left(\mathrm{~g}: \mathrm{cm}^{3}\right)$; $\mathrm{p}=0.1 \mathrm{MPa}$ )

important role in the leaching of vanadium, potassium and iron compounds. The highest increase in the degree of vanadium leaching was observed between 1 and 4 hours.

Previous studies on leaching vanadium compounds from the spent vanadium catalyst in acidic environment conducted by other authors also showed that the greatest increase in the degree of the element leaching occurs in the first hours of leaching ${ }^{15,17,21,22}$. Further extension of time results in much smaller increments of the process efficiency obtained.

Qualitative results on spent vanadium catalysts have showed the presence of vanadium at different oxidation states $(+5,+4)$ and in the form of simple and complex non-stoichiometric compounds $\left(\mathrm{V}_{\mathrm{n}} \mathrm{O}_{2 \mathrm{n}-1}, \mathrm{~K}_{3} \mathrm{~V}_{1-\mathrm{n}} \mathrm{Fe}_{\mathrm{n}}\left(\mathrm{SO}_{4}\right)_{3}\right.$ and $\left.\mathrm{KV}_{1-\mathrm{n}} \mathrm{Fe}_{\mathrm{n}}\left(\mathrm{SO}_{4}\right)_{2}\right)$. Some of these may be more or less soluble, depending on their composition. A similar behaviour was observed in the case of potassium compounds, and the leaching percentage was higher than vanadium compounds. The leaching of iron was lower and not changes in the leaching were observed in time.

Comparing the experimental data with the results published in the literature, it should be noted that in the case of vanadium compounds, the results obtained after the first hour of leaching at $293 \mathrm{~K}$ are similar to the results obtained for a $10 \%$ solution of sulphuric(VI) acid $(67 \%)^{15}$, but considerably lower than in the case of application of $15 \% \mathrm{NaOH}$ as the leaching agent $(78 \%)^{\mathbf{2 3}}$.

The effect of temperature on the degree of dissolution of the test compounds

Figure 2 shows the effect of temperature on the leaching of vanadium, potassium and iron compounds from the spent catalyst with a citric acid solution. It is clear that the higher temperature, the degree of leaching of all elements increases. In the case of vanadium and potassium compounds, the highest increase is observed when the temperature rises from 293 to $303 \mathrm{~K}$, and it is 7 and $9 \%$ respectively. The degree of dissolution of vanadium and potassium compounds at a temperature of $333 \mathrm{~K}$ is increased by 18 and $15 \%$, respectively, of that observed at $293 \mathrm{~K}$. The degree of leaching of iron compounds grows linearly with increasing temperature.

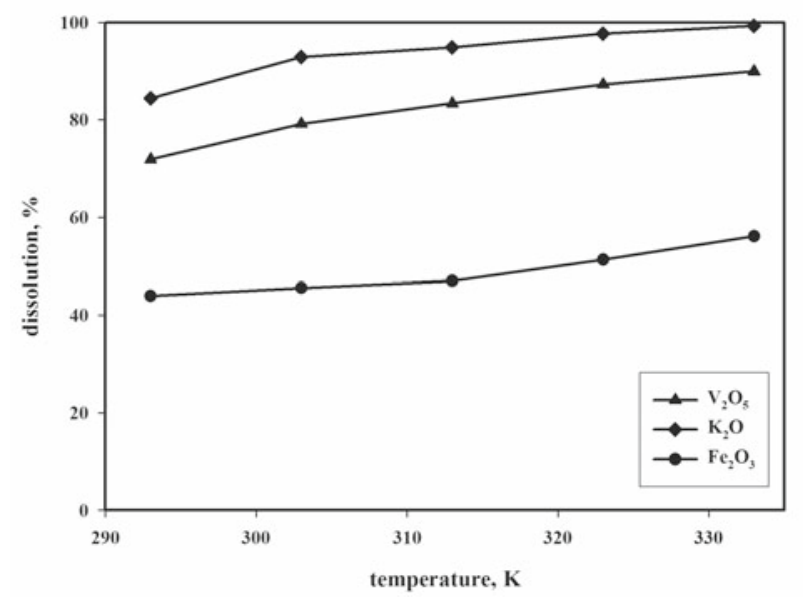

Figure 2. Effect of temperature on the dissolution of vanadium, potassium and iron compounds $(\phi=0.750-0.160$ $\mathrm{mm} ; \mathrm{cC}_{6} \mathrm{H}_{8} \mathrm{O}_{7}=10 \% ; \mathrm{t}=1 \mathrm{~h} ; \mathrm{S}: \mathrm{L}=0.1\left(\mathrm{~g}: \mathrm{cm}^{3}\right)$; $\mathrm{p}=0.1 \mathrm{MPa})$

The highest value was obtained at $333 \mathrm{~K}$, and it was $56 \%$, and the lowest $44 \%$ - at $293 \mathrm{~K}$.

The presented data show that the efficiency of leaching of spent vanadium catalyst components with a citric acid solution is dependent on temperature to a much greater extent than in the case of sulphuric(VI) acid where the effect of temperature is much less significant. Khorfan et al. $^{22}$ found that with increasing temperature from 333 to $383 \mathrm{~K}$, the yield of leaching vanadium compounds from the catalyst with $15 \% \mathrm{H}_{2} \mathrm{SO}_{4}$ grows up by only $2 \%$.

It should be noted at that the catalyst used in the tests contained relatively small amounts of iron (below 1\%). Research conducted by Grzesiak and Grobela ${ }^{11,24-27}$ on the effect of iron compounds on the properties of vanadium catalysts have shown that iron builds up in the structure of a catalyst to form compounds with vanadium $\mathrm{K}_{3} \mathrm{~V}_{1-\mathrm{x}} \mathrm{Fe}_{\mathrm{x}}\left(\mathrm{SO}_{4}\right)_{3}$ and $\mathrm{KV}_{1-\mathrm{x}} \mathrm{Fe}_{\mathrm{x}}\left(\mathrm{SO}_{4}\right)_{2}$ and without it $\mathrm{KFe}\left(\mathrm{SO}_{4}\right)_{2}$. All of these compounds are very stable chemically and completely inactive at low temperatures. In addition, the degree of their chemical inactivity increases significantly with increasing mole fraction of iron. Low iron content in the test catalyst may cause that vanadium, and potassium are more readily leached out from the spent catalyst than from a catalyst containing a much larger amount of iron in its composition.

\section{The effect of the particle size on the degree of dissolution of the test compounds}

Figure 3 shows the effect of the spent catalyst size on the degree of leaching of vanadium, potassium and iron compounds from the spent vanadium catalyst. The curves clearly show that the greatest impact of the spent catalyst size on the leaching occurs in the case of iron compounds. The increase is almost linear and with a catalyst particle size of $0.088 \mathrm{~mm}$ allows the leaching of iron compounds with a yield of about $20 \%$ higher than that achieved for the catalyst with the largest particle diameter tested. In the case of vanadium and potassium compounds, it can be clearly seen that the maximum increase in the degree of leaching is achieved when the catalyst is ground to a particle diameter of less than $0.160 \mathrm{~mm}$. Further fragmentation does not significantly affect the degree of leaching of the test compounds. 


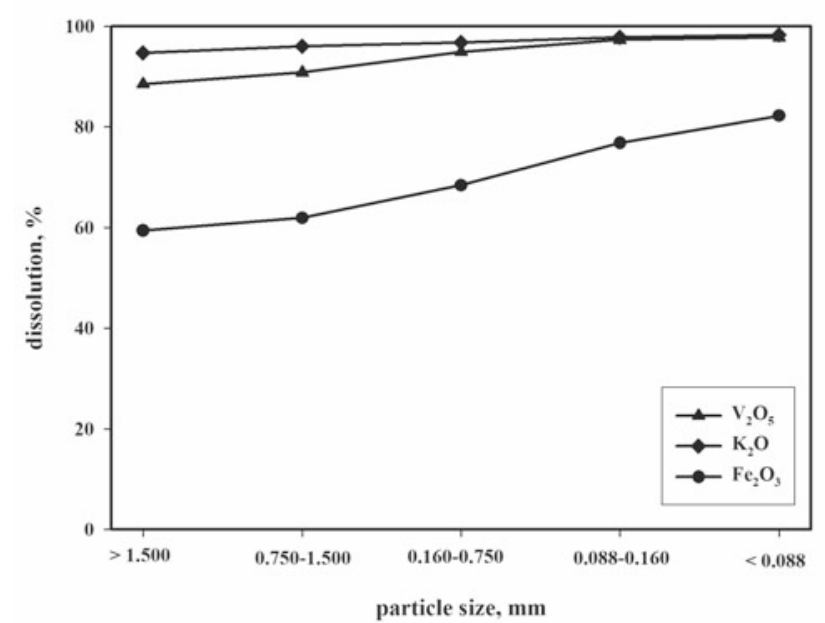

Figure 3. Particle size effect on the degree of dissolution of vanadium, potassium and iron compounds $\left(\mathrm{cC}_{6} \mathrm{H}_{8} \mathrm{O}_{7}=10 \% ; \mathrm{T}=323 \mathrm{~K} ; \mathrm{t}=4 \mathrm{~h} ; \mathrm{S}: \mathrm{L}=0.1\right.$ $\left.\left(\mathrm{g}: \mathrm{cm}^{3}\right) ; \mathrm{p}=0.1 \mathrm{MPa}\right)$

X-ray spectrometry (EDS) of the crushed catalyst conducted by Grzesiak and Grobela ${ }^{\mathbf{1 1}, 21-24}$ revealed the presence of typical spheroids resembling dendritic structures formed by the previously mentioned K-V-F-S compounds. The catalyst with particle size below $0.160 \mathrm{~mm}$ probably reduces the leaching agent access restrictions resulting from the existence of these structures.

\section{The effect of the S:L ratio on the degree of dissolution of the test compounds}

For the ratio $\mathrm{S}: \mathrm{L}=0.2$, Figure 4, the degree of leaching of vanadium, potassium and iron compounds were to 88 , 91 and $58 \%$, respectively. The higher degree of leaching is achieved at the $\mathrm{S}: \mathrm{L}$ ratio of 0.025 with recoveries of - 98, 99 and 78\%, respectively. Literature data indicate that the optimal concentration of vanadium ions in the solution to enable easy their precipitation should be in the range from 3 to $5 \mathrm{~g} \cdot \mathrm{dm}^{-3}$. Therefore, to maintain the appropriate concentration of vanadium compounds in the solution after leaching, the solid to liquid phase ratio should not be less than 0.03 .

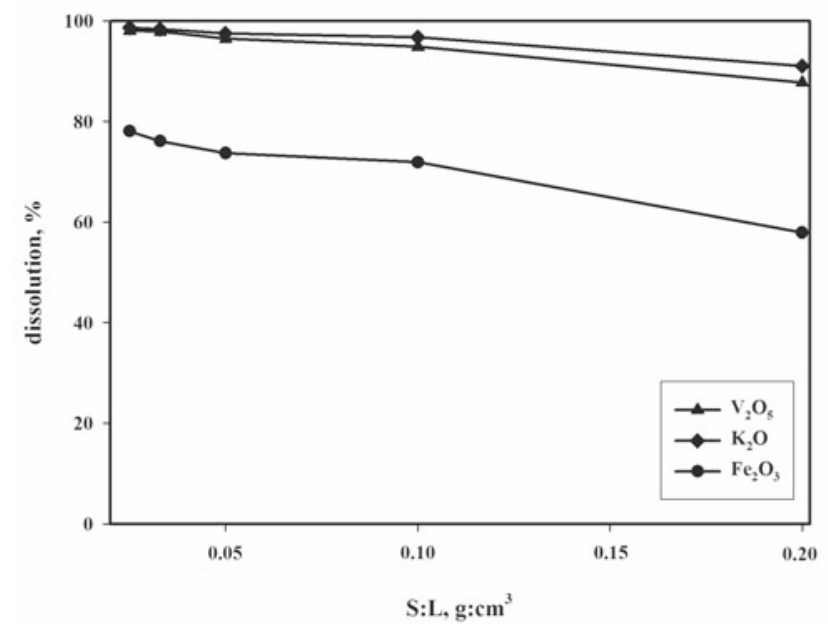

Figure 4. Effect of the S:L ratio on the dissolution of vanadium, potassium and iron compounds $(\phi=0.750-0.160 \mathrm{~mm}$; $\left.\mathrm{cC}_{6} \mathrm{H}_{8} \mathrm{O}_{7}=10 \% ; \mathrm{T}=323 \mathrm{~K} ; \mathrm{t}=4 \mathrm{~h} ; \mathrm{p}=0.1 \mathrm{MPa}\right)$

\section{CONCLUSION}

Citric acid solutions can be successfully used for leaching active phase components (vanadium and potassium compounds) from a vanadium catalyst. When the spent catalyst was treated with a $10 \%$ citric acid solution at $323 \mathrm{~K}, \mathrm{t}=4 \mathrm{~h}$, the particle size less than $0.160 \mathrm{~mm}$, and the S:L ratio below 0.1 over $90 \%$ of vanadium and potassium compounds can be leached. At the same time in addition to those elements, depending on the leaching parameters used (time, temperature, particle size, S:L), from 40 to $80 \%$ of iron compounds contained in the catalyst are leached.

The solution after leaching may be used for the production of the fresh catalyst weight. For this purpose, it is necessary to separate iron compounds from the solution (by changing the $\mathrm{pH}$ to the alkaline using $\mathrm{KOH}$ ), evaporate some water and adjust the composition of the solution by the addition of appropriate amounts of vanadium and potassium compounds. The content of citrates in the solution is very advantageous from the viewpoint of the production of new catalyst. Released in the processes of catalyst calcination and chemical formation, free carbon(IV) oxide would positively affect the structure and porosity of the catalyst.

\section{ACKNOWLEDGEMENT}

The project was funded by the National Science Centre, Poland.

\section{LITERATURE CITED}

1. Białowicz, K. \& Trypuć, M. (2011). Effect of Rosulf an L and Sulforokanol L225/1 on calcium carbonate properties. Przem. Chem. 90 (1), 148-152 (in Polish).

2. Białowicz, K. (2010). Precipitation of calcium carbonate from distillation residues and a filtrates from the solvay processat 293 K. Part 2. Processing of diluted solutions. Przem. Chem. 89 (1), 77-80 (in Polish).

3. Trypuć, M. \& Białowicz, K. (2010). Precipitation of calcium carbonate from post-distillation liquor and post-filtration liquid from Solvay process in the presence of $\mathrm{CaCO}_{3}$ crystals. Przem. Chem. 89 (10), 1357-1360 (in Polish).

4. Białowicz, K., Trypuć, M., Kiełkowska, U. (2010). Precipitation of calcium carbonate from distillation residues and a filtrates from the Solvay process at 293 K. Part 1. Processing of concentrated solutions. Przem. Chem. 89 (1), 72-76 (in Polish).

6. Białowicz, K., Trypuć, M., Kiełkowska, U. (2008). Precipitation of calcium carbonate in presence of urea. Przem. Chem. 87 (10), 1053-1056 (in Polish).

7. Trypuć, M. \& Białowicz, K. (2011). $\mathrm{CaCO}_{3}$ production using liquid waste from Solvay method. J. Clea. Prod. 19, 751-756. DOI: 10.1016/j.jclepro.2010.11.009.

8. The European Environment (State and outlook 2010). (2010). European Environment Agency: Copenhagen. DOI:10.2800/45773.

9. Report on the state of the environment in Poland 2008. (2010). GIOS, Environmental Monitoring Library: Warszawa (in Polish).

10. Grzesiak, P. (2006). Utilization of industrial wastes from sulfuric acid production process. Przem. Chem. 8-9, 1015-1019 (in Polish).

11. Grobela, M., Grzesiak, P. \& Motała, R. (2010). The influence of iron oxide on properties and durability of vanadium catalyst used in the oxidation of sulfur dioxide. Przem. Chem. 89 (2), 178-182 (in Polish). 
12. Ksibi, M., Elaloui, E., Houas, A. \& Moussa, N. (2003). Diagnosis of deactivation sources for vanadium catalysts used in $\mathrm{SO}_{2}$ oxidation reaction and optimization of vanadium extraction from deactivated catalysts. Appl. Surf. Sci. 220, 105-112. DOI: 10.1016/S0169-4332(03)00748-7.

13. Mazurek, K. (2012). Studies on the optimum conditions for leaching the spent vanadium catalyst from metallurgical plants with sodium hydroxide solutions. Przem. Chem. 91 (2), 234-238 (in Polish).

14. Mazurek, K., Białowicz, K. \& Trypuć, M. (2010). Extraction of vanadium compounds from the used vanadium catalyst with the potassium hydroxide solution. Pol. J. Chem. Techn. 12 (1), 23-28. DOI: 10.2478/v10026-010-0005-2.

15. Mazurek, K. \& Trypuć, M. (2009). Recovery of the components of the spent vanadium catalyst with sulfuric(VI) acid solutions. Przem. Chem. 88 (11), 1248-1251 (in Polish).

16. Mazurek, K. (2013). Recovery of vanadium, potassium and iron from a spent vanadium catalyst by oxalic acid solution leaching, precipitation and ion exchange processes. Hydrometallurgy 134-135, 26-31. DOI: 10.1016/j.hydromet.2013.01.011.

17. Mazurek, K., Białowicz, K., Trypuć, M. (2010). Recovery of vanadium, potassium and iron from a spent catalyst using urea solution. Hydrometallurgy 103 (1-4), 19-24. DOI: 10.1016/j. hydromet.2010.02.008.

18. Lee, F.M., Knudsen, R.D. \& Kidd, D.R. (1992). Reforming catalyst made from the metals recovered from spent atmospheric residue of desulphurisation catalyst. Ind. Eng. Chem. Res. 31 487-490. DOI: 10.1021/ie00002a006.

19. Zeng, L. \& Cheng, C.Y. (2009). A literature review of the recovery of molybdenum and vanadium from spent hydrodesulphurization catalysts. Part I: metallurgical processes. Hydrometallurgy 98, 1-9. DOI: 10.1016/j.hydromet.2009.03.010.

20. Brouwer, P. (2006). Theory of XRF. PANalytical B.V.: Almelo, Netherlands.

21. Shao, Y., Feng, Q., Chen, Y., Leming, O., Zhang, G. \& Lu, Y. (2009). Studies on recovery of vanadium from desilication residue obtained from processing of a spent catalyst. Hydrometallurgy 96, 166-170, DOI: 10.1016/j.hydromet.2008.10.005.

22. Khorfan, S., Wahoud, A. \& Reda, Y. (2001). Recovery of vanadium pentaoxide from spent catalyst used in the manufacture of sulphuric acid. Periodica Polytechnica Ser. Chem. Eng. 45, 131-137, DOI: 10.3311/pp.ch.2001-2.03.

23. Kiełkowska, U., Białowicz, K., Trypuć, M. \& Grzesiak, P. (2008). Extraction of vanadium compounds from spent vanadium catalyst using $\mathrm{NaOH}$ solution, Sulfuric acid - new opportunities, IOR Poznań, 315-322 (in Polish).

24. Grzesiak, P. \& Grobela, M. (2007). The influence of iron on the some properties of vanadium catalyst used to the $\mathrm{SO}_{2}$ oxidation process. IOR PIB: Poznań, Poland (in Polish).

25. Grzesiak, P., Grobela, M., Motała, R. (2007). The influence of the catalyst worktime on $\mathrm{SO}_{2}$ emission quantity from the sulfuric acid system and the catalyst waste material. Pol. J. Chem. Technol. 3(9), 134-137, DOI: 10.2478/v10026-007-0073-0.

26. Grzesiak, P., Grobela, M., Motała, R. \& Łukaszyk, J. (2011). Phase changes in vanadium catalysts containing iron compounds. Przem. Chem. 90 (12), 2198-2201 (in Polish).

27. Grzesiak, P., Grobela, M., Motała, R. \& Mazurek, K. (2010). Effect of recovered silica on the properties of new vanadium catalyst. Przem. Chem. 89 (4), 372-376 (in Polish). 